\title{
A computational model for the cooling phase of injection moulding
}

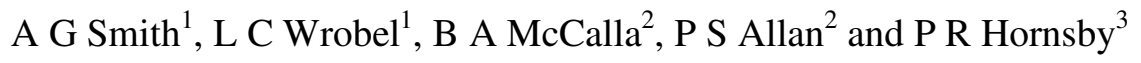

${ }^{1}$ School of Engineering and Design, Brunel University, Uxbridge UB8 3PH, UK

${ }^{2}$ Wolfson Centre for Materials Processing, Brunel University, Uxbridge UB8 3PH, UK

${ }^{3}$ School of Mechanical and Aerospace Engineering, Queen's University Belfast, Belfast BT9 5AH, UK

E-mail: andrewgsmith2001@ @otmail.com; luiz.wrobel@brunel.ac.uk; benjamin.mccalla@brunel.ac.uk; peter.allan@brunel.ac.uk; peter.hornsby@qub.ac.uk

\begin{abstract}
This paper discusses the approaches and techniques used to build a realistic numerical model to analyse the cooling phase of the injection moulding process. The procedures employed to select an appropriate mesh and the boundary and initial conditions for the problem are discussed and justified. The final model is validated using direct comparisons with experimental results generated in an earlier study. The model is shown to be a useful tool for further studies aimed at optimising the cooling phase of the injection moulding process.

Using the numerical model provides additional information relating to changes in conditions throughout the process, which otherwise could not be deduced or assessed experimentally. These results, and other benefits related to the use of the model, are also discussed in the paper.
\end{abstract}

Key words: Injection moulding, continuous cooling, computational fluid dynamics

PACS: 81.05.Lg, 47.11.+j, 44.05.+e, 44.15.+a 


\section{Introduction}

The cooling phase of the injection moulding process accounts for up to $75 \%$ of the overall cycle time. It therefore follows that a reduction in cooling time will in turn reduce the overall cycle time and hence, increase the throughput rate.

The conventional method of mould cooling is the continuous method. For continuous cooling, the cooling fluid is run through the channels of the mould continuously throughout the cycle, even during component ejection and refilling. This method, however, restricts the operating coolant temperature that can be used. If, with the objective of reducing the cycle time, the coolant temperature is set too low, the mould temperature at the start of the cycle will be below the required tool running temperature. Mould filling and surface defects on the mouldings will be consequences of this condition

When using continuous cooling, it is usual to use a coolant temperature that is close to the running temperature of the tool. The tool running temperature is the temperature required at the surface of the cavity during polymer injection (mould filling), and is predefined by the nature of the polymer. Using coolant at this temperature will ensure that the tool surface does not drop below the tool running temperature at any stage in the cycle.

Previous experimental work was carried out at Brunel University to investigate cooling methods for the injection moulding process. Coolant temperatures were assigned, taking into consideration the recommendations of the material supplier, in order that the required tool running temperature was achieved in each zone of the tool during operation [1,2]. A problem with this arrangement is that, if the cycle is interrupted, due to machine fault or change in operations, then the mould tool temperature may fall below the tool running temperature. However, as the coolant temperatures used are only a few degrees below the tool running temperature, the surface of the tool soon returns to the required temperature once operation commences, due to the addition of heat to the system from the molten polymer. 
Computational Fluid Dynamics (CFD) offers an alternative approach for analysing mould cooling, when compared to experimental methods. Commercial CFD codes incorporate solvers for both fluid flow and heat transfer problems and hence, are ideal for analysing the cooling phase of the injection moulding process. Numerical models can also provide additional information that cannot be obtained experimentally, such as surface temperatures and temperature contour fields throughout the body of the tool, enabling a greater understanding of the process. An additional benefit to employing a numerical model is that optimised solutions can be obtained in a very short time, relative to the time taken if an experimental approach is used.

Using both experimental and computational techniques, a comparison of the time taken to bring a flawless product to the market in the shortest possible time was quantified by Nardin et al. [3]. The parameters considered were product quality, optimum runner and channel locations and optimum cycle times. The results showed that it would take 7,680 minutes (5.3 days) to achieve the optimum condition experimentally, compared to 1,786 minutes (1.2 days) using a computational model.

In addition, recent developments in numerical mould filling have demonstrated that current techniques are capable of optimising mould filling conditions much faster than adopting the experimental trial and error approach [4]. This is due to computational advances, particularly processing speeds, leading to the ability to solve complex models in relatively short times.

Sridhar and Narh [5] studied the effects of applying temperature-dependent thermal properties to the polymer zone during the cooling of a plastic component. The work concentrated on the changes within the component as it cooled and solidified, and concluded that the results obtained when temperature-dependent properties were employed differed significantly from those obtained with constant thermal properties. Although there was no reference to how the given results compared with experimental data for the polymer and component, the paper highlighted the importance of including temperature-dependent thermal properties when conducting simulations involving molten polymers. 
The objective of the work presented in this paper was to construct and validate a computational fluid dynamics model, using continuous cooling results obtained experimentally, in order to gain greater understanding of the cooling phase of injection moulding, with a view to optimising the process.

\section{Experimental Details and Setup}

An illustration of the tool used can be seen in figure 1, while figure 2 details the component produced during the experimental work. The moulded component can also be seen in figure 3 . It consists of three distinct sections: a central tube $2 \mathrm{~mm}$ thick, a box section $2 \mathrm{~mm}$ thick and two tensile test bars $4 \mathrm{~mm}$ thick.

Three distinct tool zones can be identified in figure 1. They are the fixed zone (fixed to the moulding machine), the moving zone (which retracts to open the mould tool) and the insert zone. The fixed and moving zones are made up of an inner and an outer tool section, which form the tool zones.

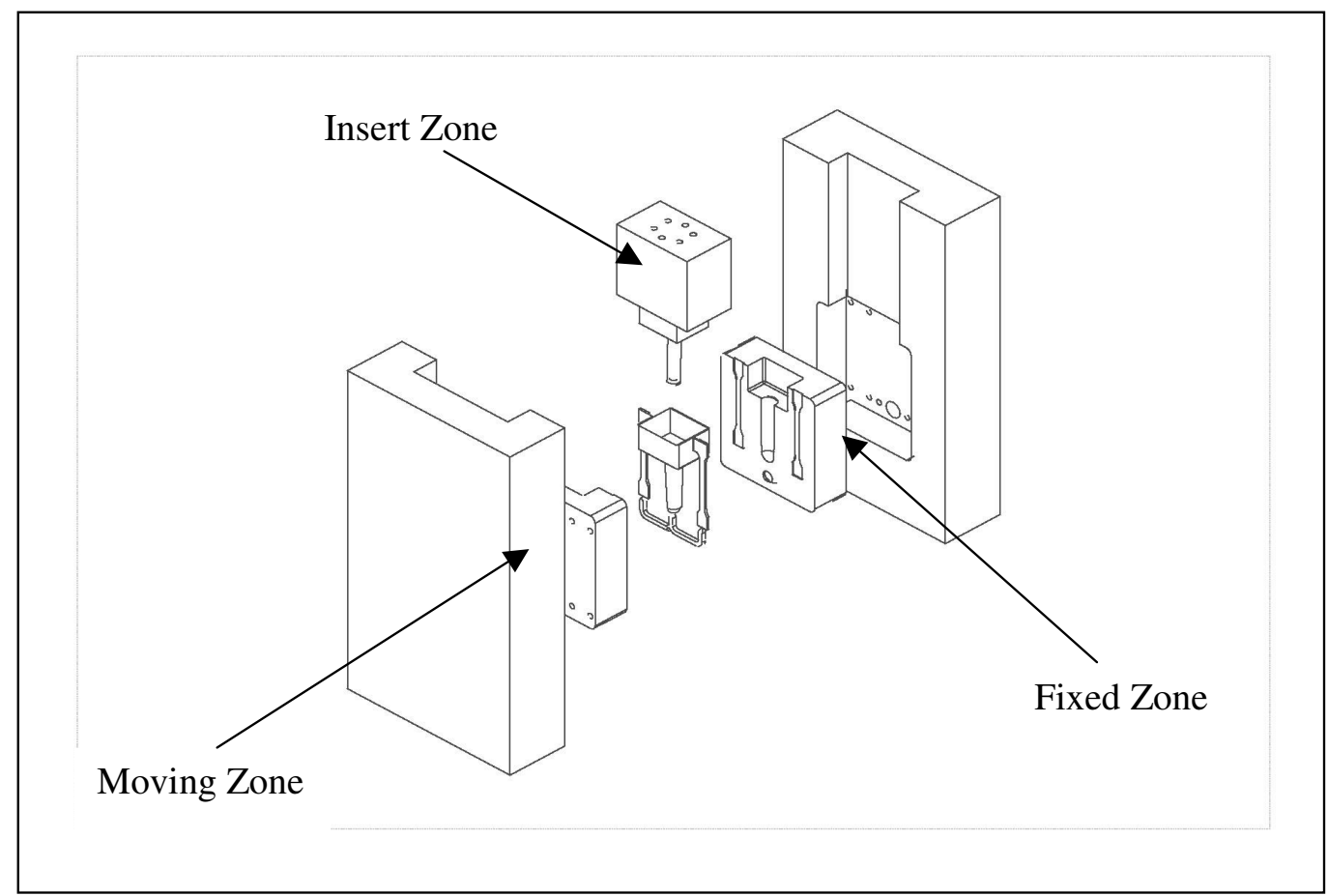

Figure 1: Illustration of the mould tool zones 


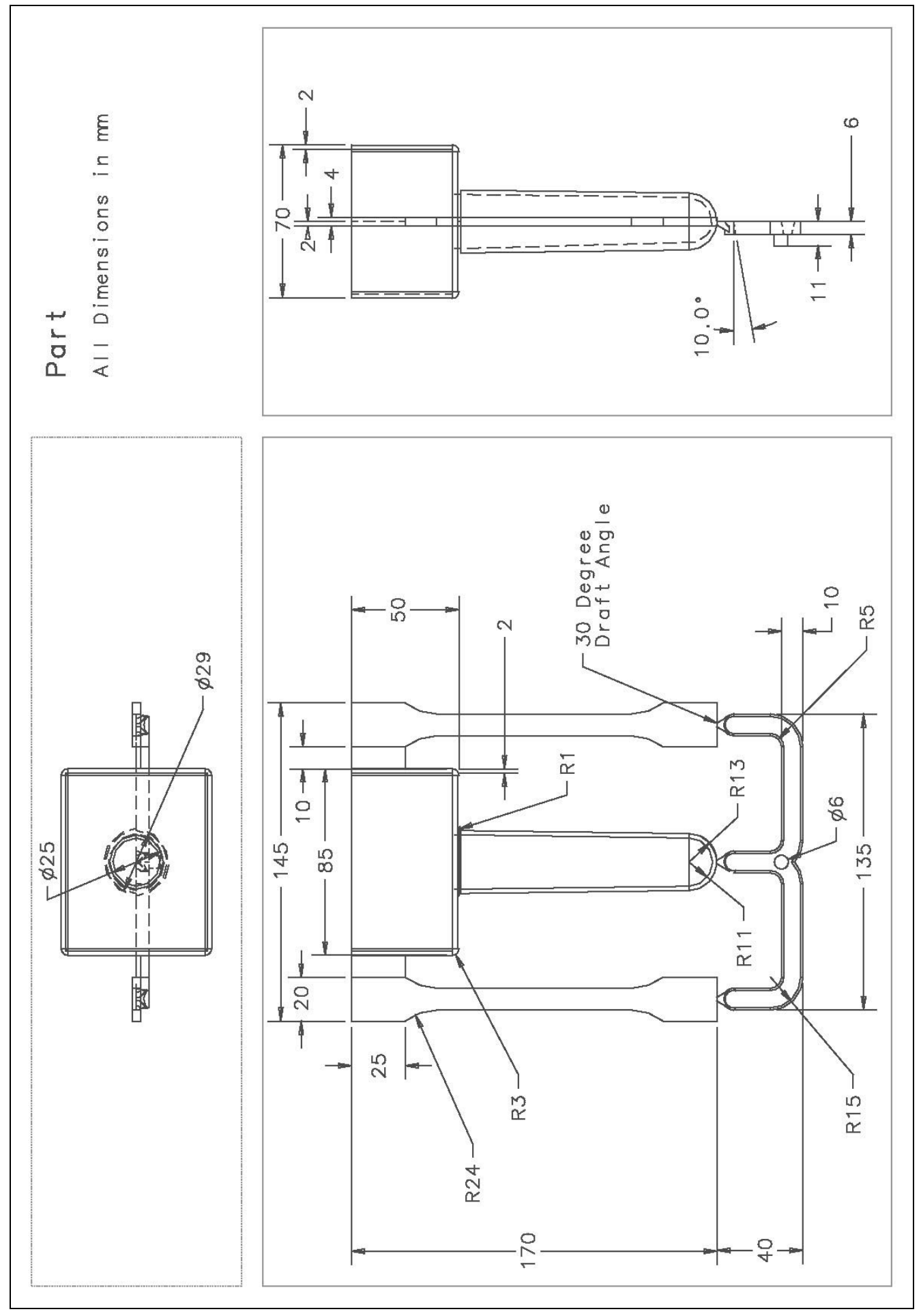

Figure 2: Component drawing complete with runners 


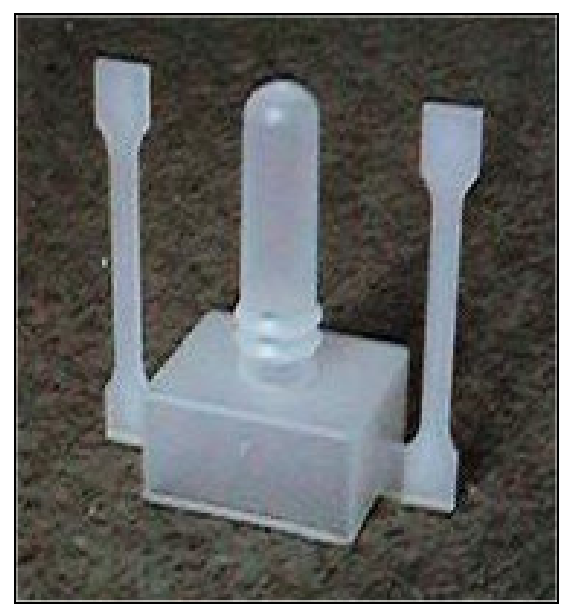

Figure 3: Polypropylene moulded test piece

During all the experiments, data were collected at a number of pressure/temperature transducers located at the surface of the tool cavity, in contact with both the molten polymer and mould tool (figure 4). For the purpose of comparison with the computational model, data obtained from the sensors located at the ends of the tensile test bars (closest to the injection gates), in both the fixed and moving zones of the tool, were used. In this paper, data are only presented for the sensor located in the fixed half of the tool, as the difference for the two zones was negligible, due to similar geometries. The fixed zone sensor is referred to as the primary sensor throughout this paper.

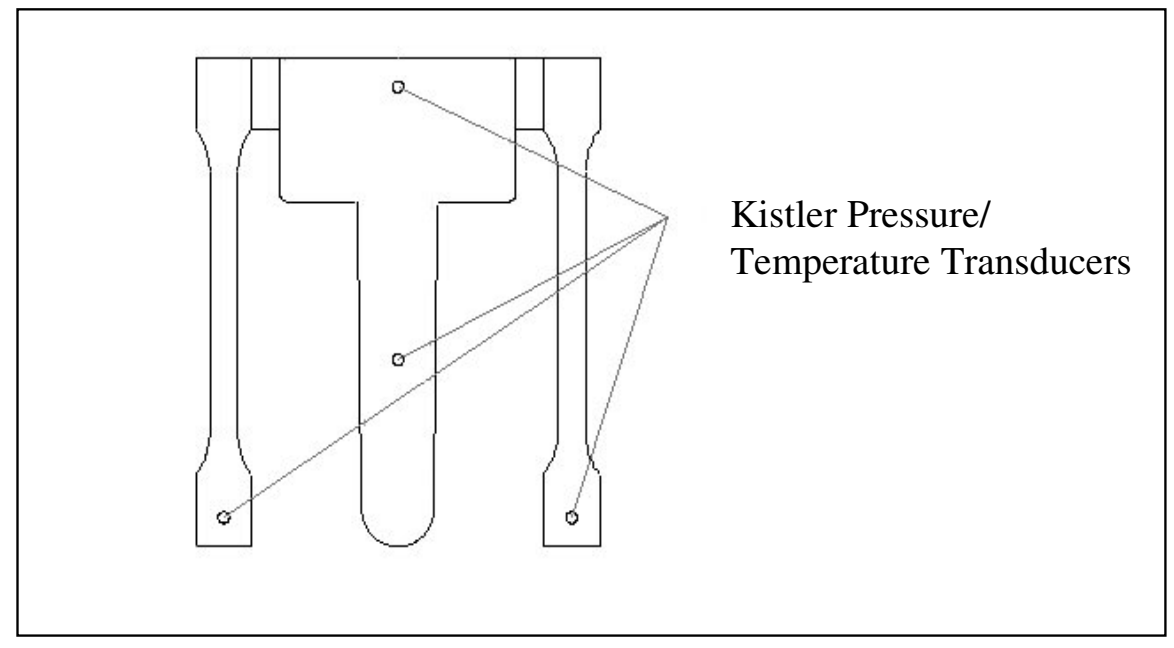

Figure 4: Pressure/Temperature Sensor Locations 
Experimentally, cooling times are defined as the time taken for the pressure at the primary sensor to return to atmospheric, after the injection of a consecutive shot. The molten polymer cools and solidifies in the mould, causing the pressure at the sensor to drop. The point at which the pressure returned to atmospheric was found to correlate directly with a value of temperature at the same sensor location. Figure 5 provides information related to the temperature at the primary sensor at the point when the pressure drops to zero, which will be referred to as the ejection temperature at the primary sensor (when the component has reached the ejection temperature). This temperature was found to be $60^{\circ} \mathrm{C}$, to the nearest $2^{\circ} \mathrm{C}$, when the pressure returned to atmospheric.

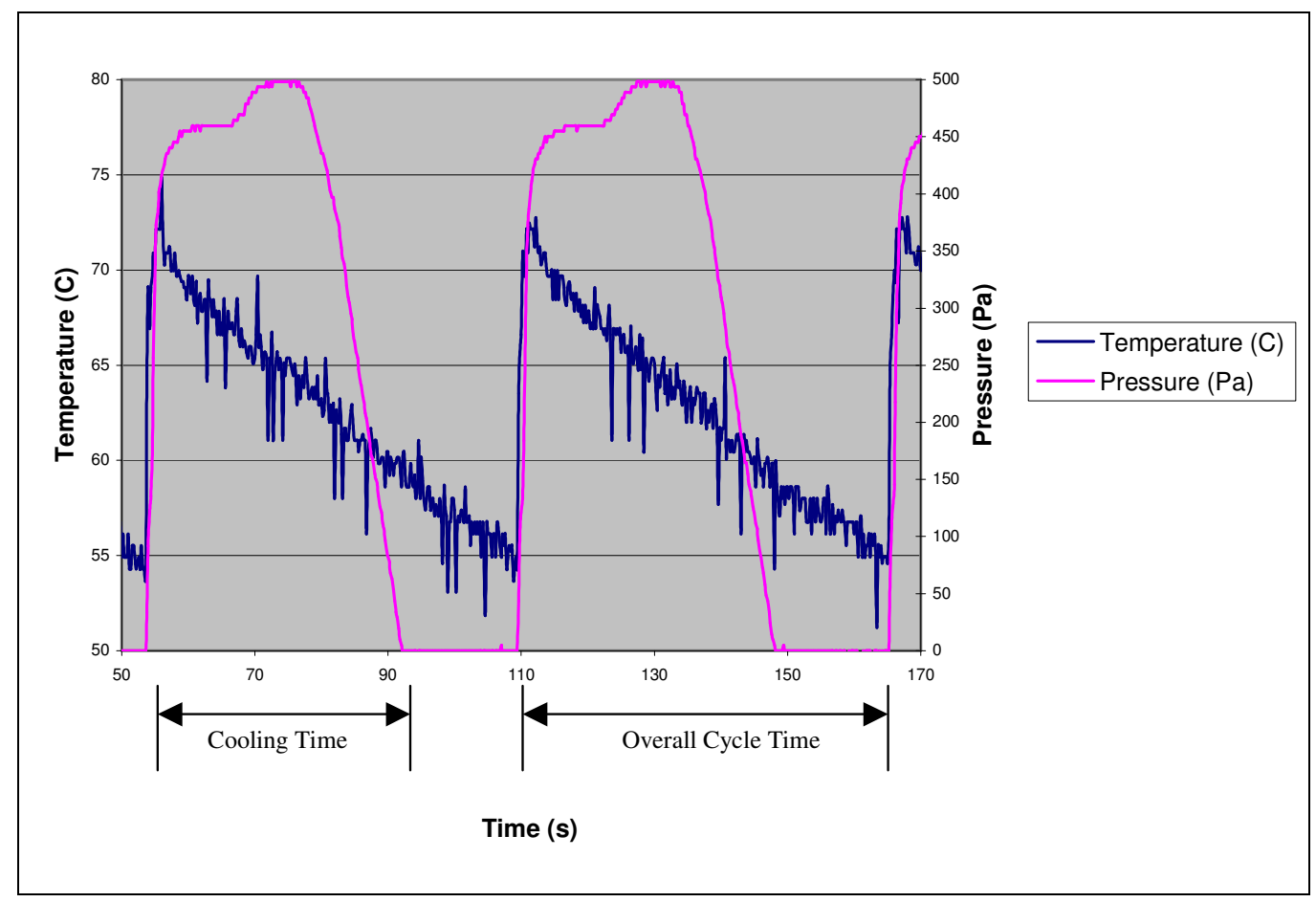

Figure 5: Temperature and pressure traces at the primary sensor for continuous cooling over two cycles

The time taken for mould opening, component ejection, mould closing and polymer injection accounted for the difference between cooling and cycle times. Once the component had cooled, there was a time delay before the mould was re-filled due to 
these additional elements of the cycle. The overall cycle time consists of mould filling time, cooling time and ejection time, while the objective of the computational simulation is to analyse and reduce cooling time. Therefore, injection and ejection times were kept constant. Multiple cycles were modelled to allow the system to stabilise, with consistent cycle times for consecutive cycles.

All the results displayed correspond to a tool running temperature of $50^{\circ} \mathrm{C}$. The material used was a polypropylene homopolymer, Moplen SM6100, which was injected into the mould at a melt temperature of $220^{\circ} \mathrm{C}$. This was the temperature at the barrel nozzle. Temperature changes due to shear effects encountered by the melt as it was injected into the mould cavity were not evaluated.

Coolant temperatures below the tool running temperature were used in order to prevent the tool from overheating. The coolant temperature in the fixed zone was the lowest of the three zones, to compensate for the heat supplied by the hot runner system. The coolant temperatures for the zones were set during moulding, based on the temperatures recorded by the REPS AP 1/8 probe zone sensors [6] positioned within the three zones of the tool. The coolant temperatures were adjusted until the zone sensors gave a reading close to $50^{\circ} \mathrm{C}$ throughout the cycle. The locations of these sensors, with respect to the component, can be seen in figure 6 .

The coolant temperatures for the three zones that gave a corresponding tool running temperature of $50^{\circ} \mathrm{C}$ were $38^{\circ} \mathrm{C}$ for the fixed zone, $46^{\circ} \mathrm{C}$ for the moving zone and $48^{\circ} \mathrm{C}$ for the insert zone. The temperature measured at the sensors within the fixed and moving zones was found to fluctuate between $50^{\circ} \mathrm{C}$ and $52^{\circ} \mathrm{C}$ during each moulding cycle, whereas the temperature fluctuated between $44^{\circ} \mathrm{C}$ and $57^{\circ} \mathrm{C}$ in the insert zone. 


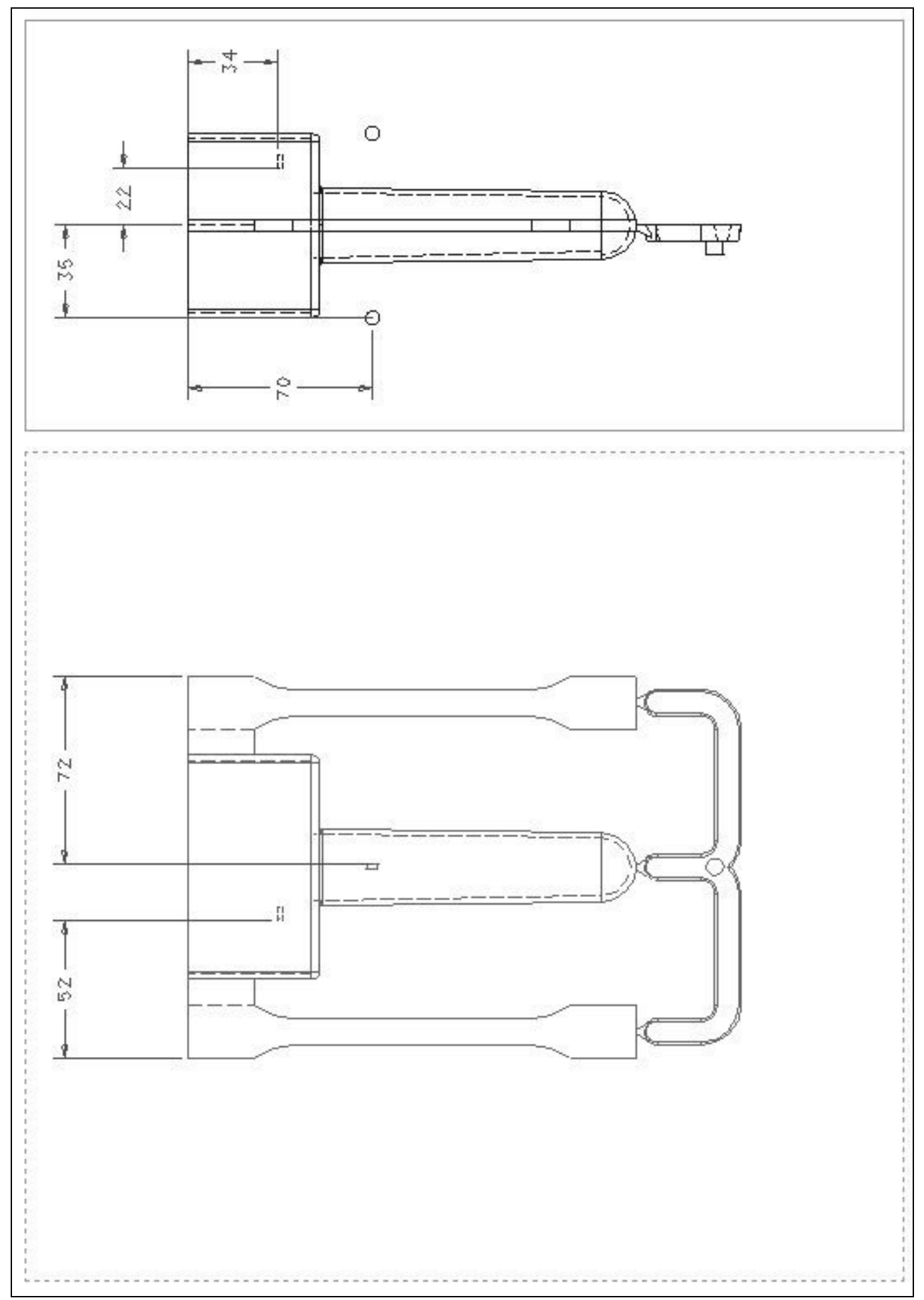

Figure 6: Zone sensor locations in relation to the part cavity 


\section{Computational Setup}

The component and tool were considered as solids, thus only conduction heat transfer from the component to the tool takes place in this part of the model. The coolant fluid in the channels was modelled using a viscous, $\mathrm{k}-\varepsilon$ turbulence model, to simulate the convective/conductive heat transfer from the tool to the channels and surrounding air, and to ensure that the flowing coolant removes the correct quantity of heat.

There are a number of procedures to follow in order to generate a suitable numerical model for analysing any process. These are summarised below and include geometry and mesh selection, setup of the numerical solver, and assignment of boundary and initial conditions.

\subsection{Geometry and Mesh Selection}

The final geometry was created to be identical to the tool used for the experimental work. Only half of the tool was modelled for the simulations, as a plane of symmetry exists, splitting the three zones of the tool (see figure 7).

The geometry was created using I-DEAS version 10 and then exported as an IGES file, which was later imported into GAMBIT 2.0. Procedures were followed in order to ensure that all tool sections were connected and all coincident faces were removed. Once imported into GAMBIT, boundary and initial conditions were applied and the solid and fluid domains meshed, prior to exportation to FLUENT 6.0.

Mesh-independence tests were carried out with varying levels of refinement. The results of these tests confirmed the suitability of the chosen mesh, which contained approximately 2,000,000 tetrahedral elements. The interval size within the component and the channels was $0.85 \mathrm{~mm}$ and $1.75 \mathrm{~mm}$, respectively, resulting in a mesh that was most refined in the areas of greatest interest (figure 8). 


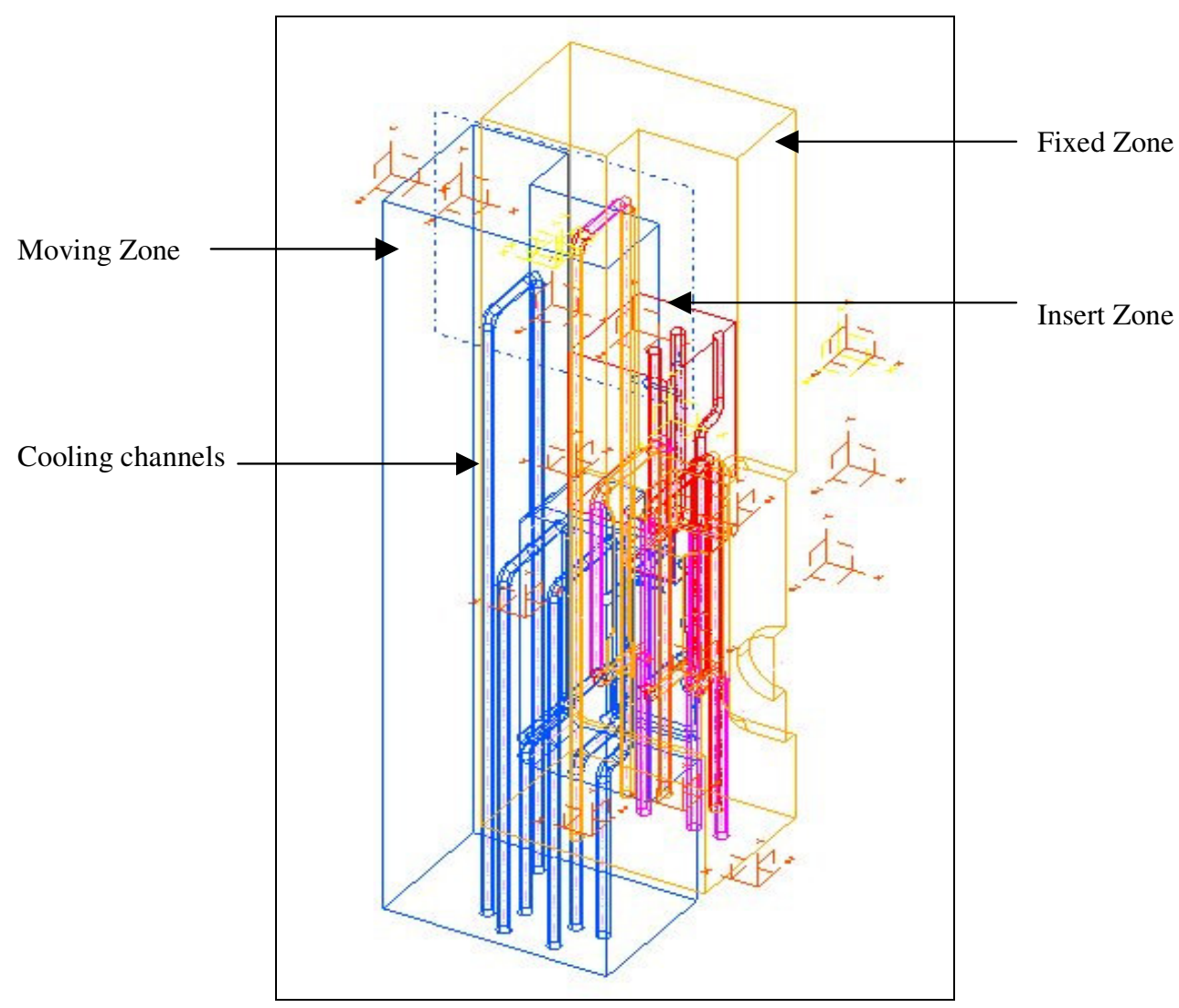

Figure 7: Pictorial representation of the final geometry of the cooling channels in the experimental mould tool 


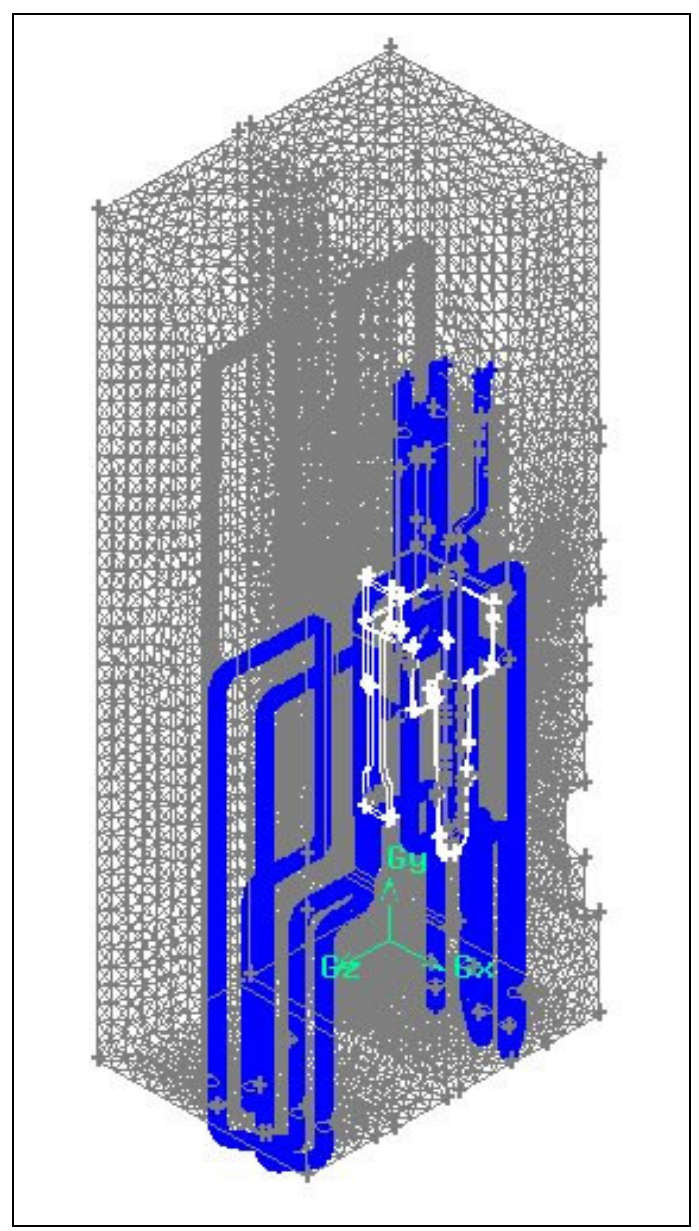

Figure 8: Pictorial representation of the final mesh

\subsection{Numerical Model Setup}

The numerical model was setup as three-dimensional and unsteady, using a segregated, first-order implicit solver. Temperature-dependent thermal properties, implemented in FLUENT as user-defined functions, were assigned for the component, while constant thermal properties were used for the tool and coolant. The expressions defining the density, specific heat and thermal conductivity of the component were obtained as piecewise linear variations from the curves presented by Stevenson [7], as follows: 
Density:

$$
\begin{array}{ll}
\rho=\frac{77500}{0.026(T-50)+86.8} & \text { for } 127.5^{\circ} \mathrm{C}>\mathrm{T}>50^{\circ} \mathrm{C} \\
\rho=\frac{5000}{0.069(T-127.5)+5.73} & \text { for } 132.5^{\circ} \mathrm{C}>\mathrm{T}>127.5^{\circ} \mathrm{C} \\
\rho=\frac{87500}{0.08(T-132.5)+106.3125} & \text { for } \mathrm{T}>132.5^{\circ} \mathrm{C}
\end{array}
$$

Specific heat:

$$
\begin{array}{ll}
C=\frac{(T-50)}{170}+1.95 & \text { for } 90^{\circ} \mathrm{C}>\mathrm{T}>50^{\circ} \mathrm{C} \\
C=\frac{8.3147(T-90)}{15}+2.1853 & \text { for } 105^{\circ} \mathrm{C}>\mathrm{T}>90^{\circ} \mathrm{C} \\
C=\frac{-8.1676(T-105)}{10}+10.5 & \text { for } 115^{\circ} \mathrm{C}>\mathrm{T}>105^{\circ} \mathrm{C} \\
C=\frac{0.6176(T-115)}{105}+2.3324 & \text { for } \mathrm{T}>115^{\circ} \mathrm{C}
\end{array}
$$

Thermal conductivity:

$$
\begin{array}{ll}
K=\frac{0.006(T-50)}{75}+0.216 & \text { for } 125^{\circ} \mathrm{C}>\mathrm{T}>50^{\circ} \mathrm{C} \\
K=\frac{-0.052(T-125)}{7.5}+0.222 & \text { for } 132.5^{\circ} \mathrm{C}>\mathrm{T}>125^{\circ} \mathrm{C} \\
K=\frac{0.007(T-132.5)}{87.5}+0.170 & \text { for } \mathrm{T}>132.5^{\circ} \mathrm{C}
\end{array}
$$

while the thermal properties of the tool and coolant are as follows:

Tool (plain carbon steel) [8]:

$\begin{array}{ll}\text { Density } & =7,700 \mathrm{~kg} / \mathrm{m}^{3} \\ \text { Specific heat } & =460 \mathrm{~J} / \mathrm{kgK} \\ \text { Thermal conductivity } & =20 \mathrm{~W} / \mathrm{mK}\end{array}$

Coolant (water) [8]:

Density $\quad=998.2 \mathrm{~kg} / \mathrm{m}^{3}$ 
Specific heat, $=4,182 \mathrm{~J} / \mathrm{kgK}$

Thermal conductivity $=0.6 \mathrm{~W} / \mathrm{mK}$

\subsection{Boundary and Initial Conditions}

\subsubsection{External Surfaces of the Tool}

Symmetry faces were assigned a zero heat flux by default, while all other external faces of the tool had a convective heat transfer coefficient of $15 \mathrm{~W} / \mathrm{m}^{2} \mathrm{~K}$. This follows information related to free and forced convection of gases over various surfaces, that suggests a range of values between 2 and $25 \mathrm{~W} / \mathrm{m}^{2} \mathrm{~K}$ [9]. Although accurate values for convective heat transfer coefficients can only be found experimentally, the above value was selected because the surface of the tool was smooth and, therefore, the flow of air within the boundary layer was not restricted by large surface asperities. In addition, the tool itself was in a well-ventilated workshop, so air was relatively free to flow around the tool. The free stream temperature (or temperature within the surrounding workshop environment) was set to $27^{\circ} \mathrm{C}$.

\subsubsection{Channel Inlets and Outlets}

Flow in the cooling channels was simulated using a k- $\varepsilon$ turbulence model, with water acting as the cooling fluid. One of the water heaters used on the experimental tool setup was a Conair $6 \mathrm{~kW}$ unit. These units are capable of delivering water at a nominal rate of $951 / \mathrm{min}$, at a pressure of 0.9 bar. Thus, the coolant velocity was calculated using the supply pressure for the water heater pump. This value was then checked against the nominal flow rate, to ensure that the pump was capable of delivering coolant at the calculated velocity. It was assumed that the water pump was responsible for elevating the water to a height of 2 metres above the height of the pump. Using Bernoulli's equation and neglecting losses due to friction within the pipes gave a velocity value of $12 \mathrm{~m} / \mathrm{s}$, which was used as the channel inlet velocity.

In addition to the velocity at the inlet, the turbulence characteristics were defined using the turbulence intensity and length scale. Using the FLUENT 6.0 User Guide [8], the estimated values of turbulence intensity and length scale were $I=6.6 \%$ and $l$ $=0.07 d$, respectively, with $d$ representing pipe diameter. 


\subsubsection{Solid/Fluid Interface}

The solid/fluid interfaces were modeled as coupled walls, so that the values in either zone could be evaluated and the interaction between the two could be assessed. This condition basically assumes compatibility of temperature and velocity (in this case, zero velocity) at the interfaces.

A simple two-dimensional simulation of flow through a channel with thick walls was initially conducted, in order to analyse the heat transfer through the solid/fluid interface (representative of the heat transfer between the tool and the cooling channels). Different meshes with greater levels of refinement closer to the wall were tested. The results showed that using a coarse mesh in the channel was normally sufficient to accurately represent the transfer of heat from the tool to the channel, although the flow characteristics within the channel may not be accurately represented.

\subsubsection{Initial Conditions}

Initially, the tool was set at the running temperature of $50^{\circ} \mathrm{C}$ and the component was set at the polymer injection temperature of $220^{\circ} \mathrm{C}$. As the flow was transient with consecutive shots, a repeating process was modelled with various conditions changed throughout the simulation. The injection of a consecutive shot, once the previous component had cooled sufficiently and reached the ejection temperature, was done manually by temporarily interrupting the transient simulation and re-patching the temperature in the part zone at the injection temperature of $220^{\circ} \mathrm{C}$. This manual process was done 10 seconds after the temperature at the primary sensor reached the ejection temperature, as this allowed sufficient time to account for tool opening, part ejection, tool closing and polymer re-injection.

Since the purpose of this investigation was to analyse the cooling phase of the injection moulding cycle only, the difference between cycle time and cooling time was kept constant throughout the simulation, even though this was not the case for some of the experimental work. Experimentally, this time ranged between 10 and 20 seconds. 
In order to validate the numerical model, the coolant temperatures used were the same as those used experimentally, except in the fixed zone. The coolant in the fixed zone was at $38^{\circ} \mathrm{C}$ in the experimental set-up, in order to remove the excess heat supplied by the hot runner system. In the computational model, the coolant temperature in both the fixed and moving zones was set at $46^{\circ} \mathrm{C}$ and the coolant in the insert zone was set at $48^{\circ} \mathrm{C}$, as the hot runners were not modelled.

\section{Results and Discussion}

All the results discussed in this section were used to validate the model. The data displayed directly correlate with the data obtained experimentally, along with additional useful data collected using the model, which could not be easily obtained using the experimental set-up. Temperature data were collected at the sensor locations discussed previously. In addition, data were collected relating to the minimum temperature on the cavity surface in each zone.

Figure 9 demonstrates that it took approximately 7 cycles for the rate of heat transfer into and out of the tool to stabilise. Therefore, there was no net heat being taken in by the tool, across a cycle, after this time. This represents the point at which the heat profile throughout the tool was the same at the start and end of a cycle. Experimental results were taken once this condition was reached, as the sample data were taken after a large number of components had been produced.

Figure 10 looks more closely at two full cycles after the system has stabilised. It can be seen from this figure that the overall cycle time was 52 seconds. This corresponds to a cooling time of 42 seconds. This figure is important for the validation for the computational model, as it graphically compares the computational and experimental temperature readings at the primary sensor, across two complete cycles. The time axis has been altered so that the results are in phase at the start of the first cycle for ease of comparison.

These results are very promising as the differences between the two data sets can be

explained and justified. It can be seen that the experimental cycle time is around 4 
seconds longer than the computational one (56 seconds). This is partly because the experimental difference between cooling time and cycle time can reach up to 17 seconds, but was taken to be 10 seconds in the computational model at all cycles. Therefore, the experimental cooling time was 39 seconds, compared to a computational cooling time of 42 seconds. This is a difference of around $7.5 \%$.

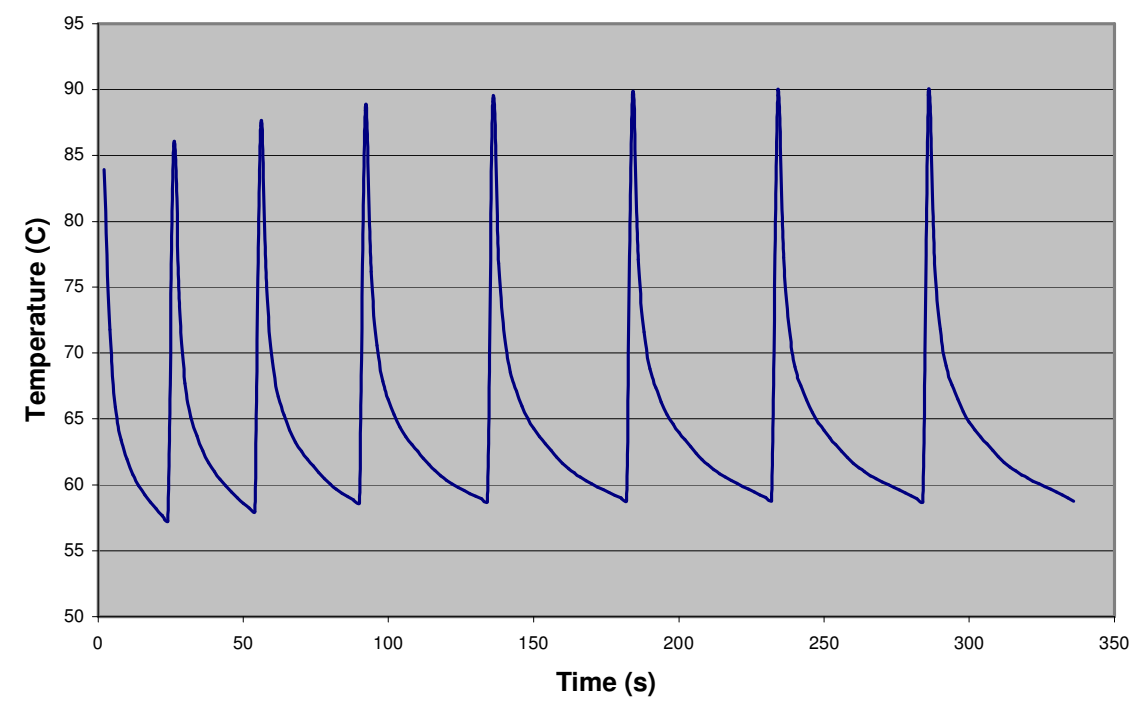

Figure 9: Temperature calculated at the fixed sensor for continuous cooling 


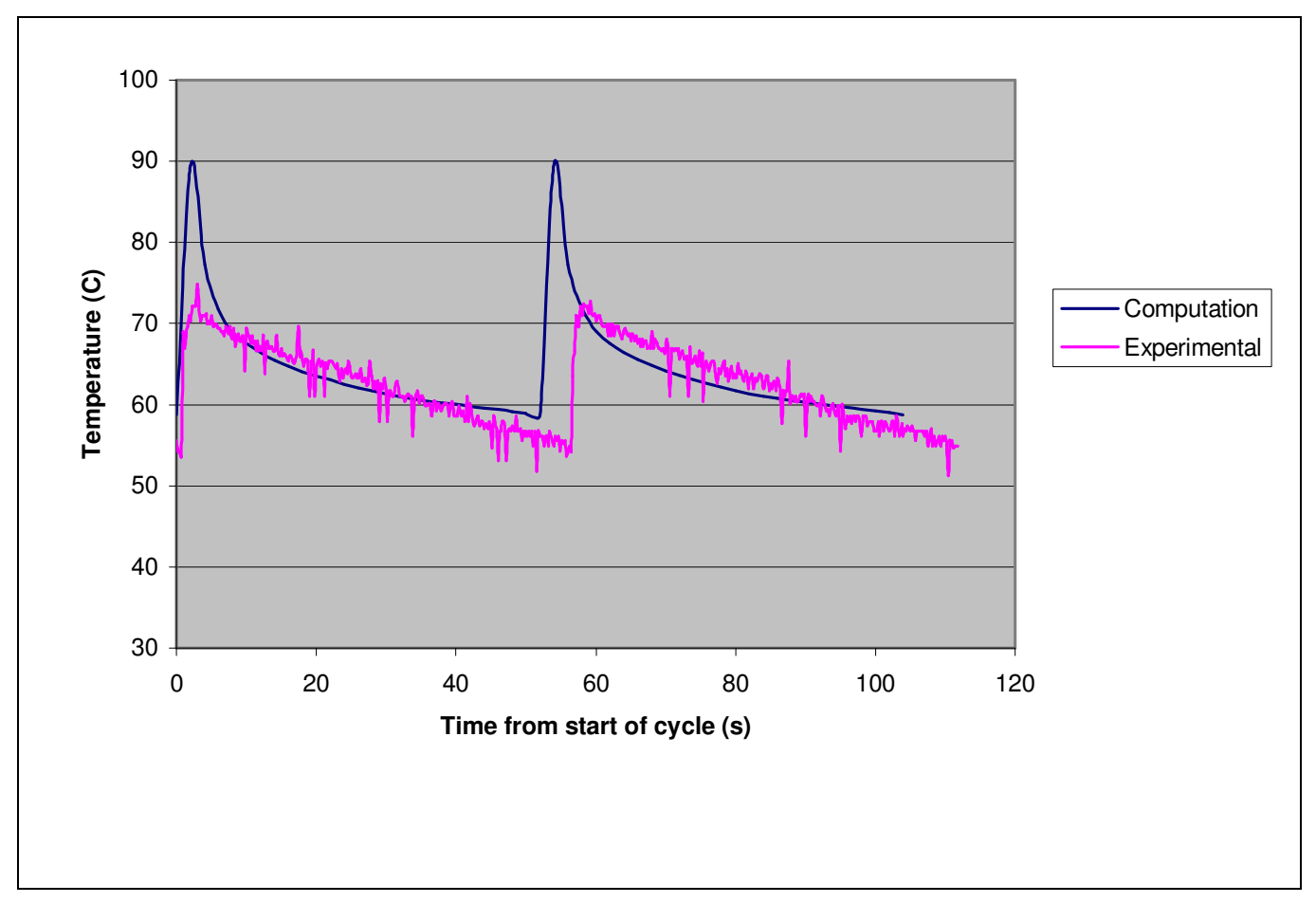

Figure 10: Comparison of computational and experimental temperature plots over two cycles taken at the position of the primary sensor

Although relatively large differences in maximum and minimum temperatures can be seen at the primary fixed sensors, the reasons for this are again justifiable. In the experimental setup, the surface sensor was set into the cavity surface, therefore the temperature of the surrounding tool also contributed to the measured temperature. In the case of the computational model, the sensor has a negligible thickness and so an average of the temperatures either side of the interface was reported. As the tool was at a lower temperature than the polymer, the experimental reading was found to be lower, as a greater proportion of the sensor was in contact with the tool.

The benefits of using a computational model should also be highlighted. It allows the monitoring of maximum and minimum temperatures on any given surface, and also allows the viewing of temperature contour plots on any chosen surface. This enables the visualisation of temperature distributions throughout the tool.

Figure 11 shows a contour plot taken at the end of the final cycle. The coolant temperatures used in each zone are given in section 3.2 and the final cycle time was 
52 seconds. The viewing surface is a planar cut in the $\mathrm{X}-\mathrm{Z}$ plane, taken through the cross section of the tool at the height of the primary sensors. This enabled the observation of the temperature distribution through the body of the tool, something the experimental model was unable to do. Consequently, this will be a valuable tool when examining ways to optimise cooling times for the injection moulding process.

Figure 12 shows one of the significant advantages of using a numerical model to analyse this system. An important factor that affects the properties of injectionmoulded components is the temperature at the surface of the cavity prior to the injection of consecutive shots. It can be seen that the minimum computed temperature at the surface of the cavity was found to be $48^{\circ} \mathrm{C}$ in the fixed and moving zones, prior to mould filling. This highlighted the need for some change to the experimental setup. Increasing the coolant temperature in the two zones would increase the minimum cavity temperature at the end of the cycle.

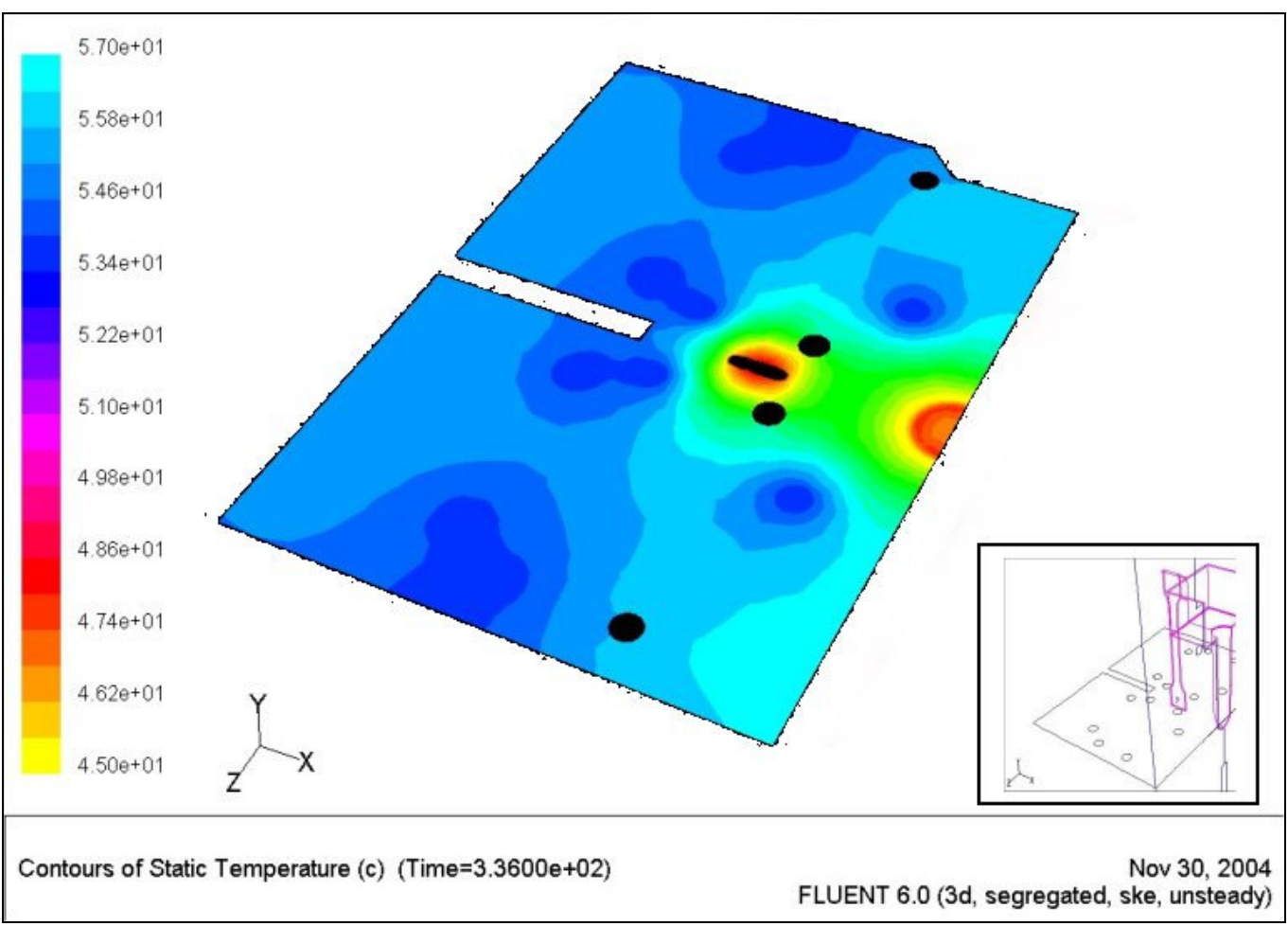

Figure 11: Temperature contour plot taken through the body of the tool using the computational model 


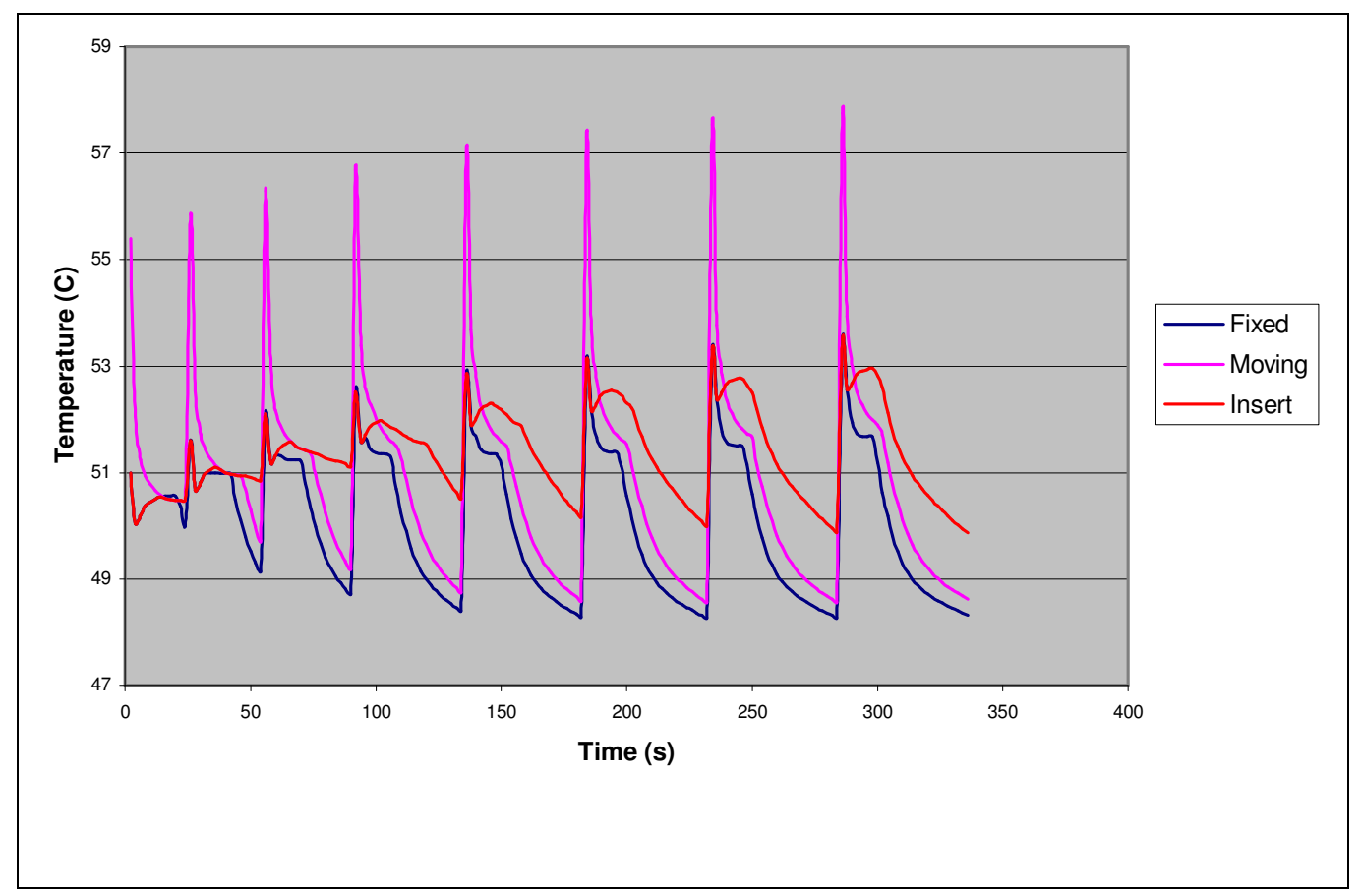

Figure 12: Minimum temperature at the cavity surface in each zone

Figure 13 shows a contour plot of the fixed and moving halves' cavity surfaces at the end of the final cycle. The coolant temperatures used in each zone are given in section 3.2 and the final cycle time was 52 seconds. This clearly shows that the temperature at certain places on the surface dropped below the running temperature, and serves as a tool to predict where this will occur.

Figures 11 and 13 demonstrate how using a colder coolant could reduce cycle time. An equilibrium state is reached, whereby the cold front caused by the channels counteracts the hot front caused by the component. All of the residual heat from the hot polymer is removed from the tool by the cold front, prior to injection of a consecutive shot. 


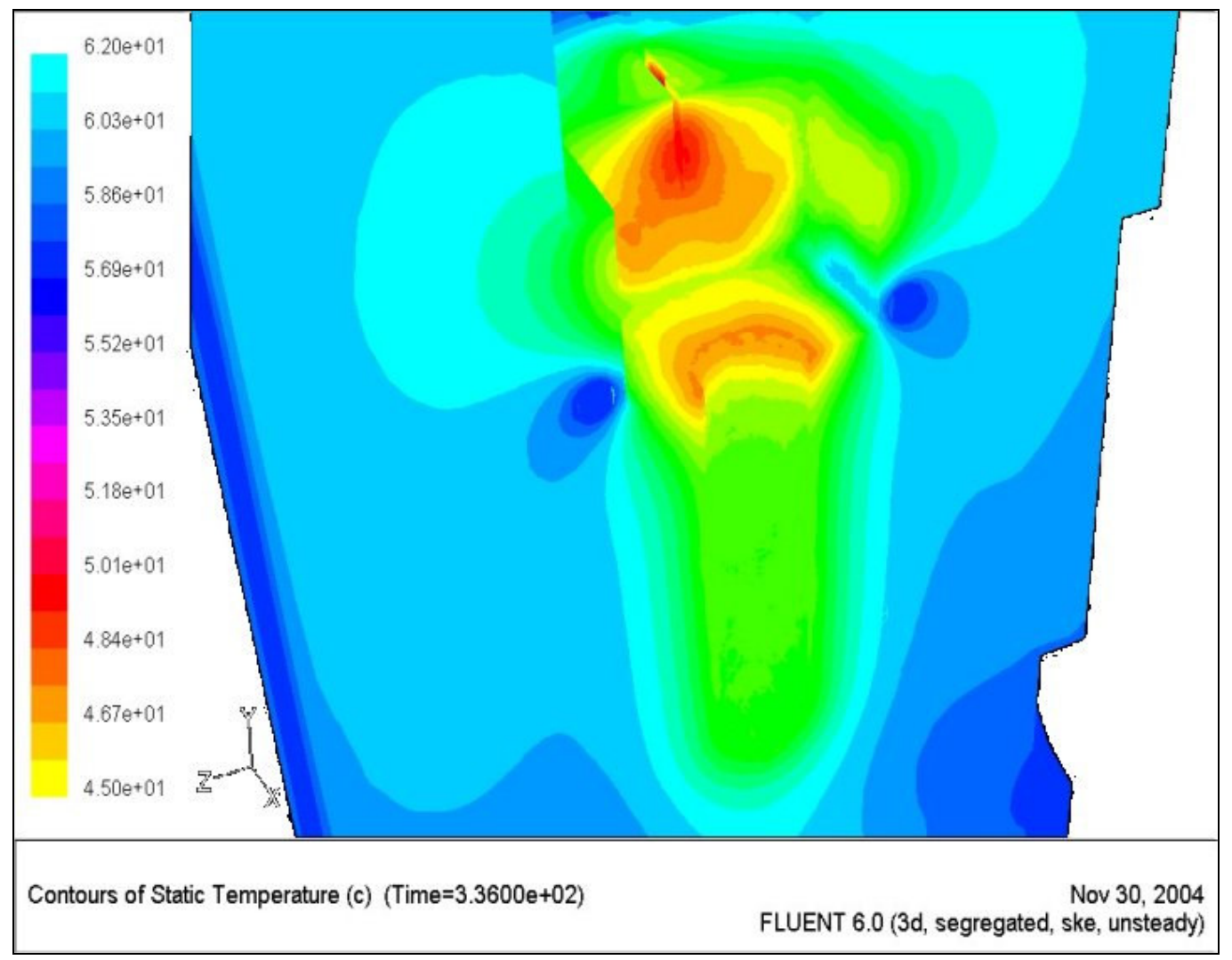

Figure 13: Temperature contour plot taken at the cavity surface of the tool using the computational model

\section{Conclusions}

The results show that the computational model generated in this study is capable of producing accurate results when compared to the experimental data. The model can determine the true mould cavity temperatures over the whole mould surface, whereas experiment is confined to a limited number of point locations on the surface. In addition, the temperatures recorded in practice are not an accurate representation of the cavity surface temperature. The graphic displays that can be generated by the model can be used to evaluate a potential mould cooling configuration in advance of tool manufacture.

The computational model has been successfully validated, and can now be used for the optimisation of the cooling phase of the injection moulding process. 


\section{Acknowledgments}

The work described in this paper forms part of the Enhanced Polymer Processing programme funded by the EPSRC, in collaboration with the University of Bradford and Queen's University Belfast. The authors would like to acknowledge the technical support received from REPS Ltd and John Guest Ltd for the provision of the experimental mould tool.

\section{References}

[1] B.A. McCalla, P.S. Allan, P.R. Hornsby, A.G. Smith, L.C Wrobel, A.L. Kelly and P.D. Coates, Evaluation of pulsed cooling in injection mould tools, Polymer Process Engineering 03, 52-71, Ed P.D. Coates, University of Bradford (2003)

[2] B.A. McCalla, P.S. Allan, P.R. Hornsby, Evaluation of heat management in injection mould tools, Plastics, Rubber and Composites: Macromolecular Engineering, 36, 26-33 (2007)

[3] B. Nardin, K. Kuzman, Z. Kampus, Injection moulding simulation results as an input to the injection moulding process, Journal of Materials Processing Technology 130, 310-314 (2002)

[4] S.W. Kim, L.S. Turng, Developments of three-dimensional computer-aided engineering simulation for injection moulding, Modelling and Simulation in Materials Science and Engineering 12, S151-S173 (2004)

[5] L. Sridhar, K. A. Narh, The effect of temperature dependent thermal properties on process parameter prediction in injection moulding, International Communications in Heat and Mass Transfer 27, 325-332 (2000)

[6] R. E. Promotion Services Ltd. (REPS), Temperature sensing probes, [http://fp.repsuk.plus.com/products/probes.htm] (accessed 8/10/03)

[7] J. F. Stevenson, Innovation in Polymer Processing - Moulding, Hanser \& Gardener Publications Inc., pp. 425 - 430 (1996)

[8] Fluent 6.0 User Guide, Fluent Inc. (2003)

[9] Engineering.com, Typical values of convection heat transfer coefficient, 
[http://www.engineering.com/content/ContentDisplay?contentId=41005014]

(accessed 17/03/2004)

23 of 23 